\title{
Study on the Development Strategy of Urban Public Fitness Equipment
}

\author{
Wei $\mathrm{He}^{1}$, Wanxiang $\mathrm{Li}^{2}$ \\ ${ }^{1}$ School of Art and Design, Lanzhou Jiaotong University, Lanzhou, Gansu, 730070 \\ ${ }^{2}$ School of Mechanical and Electrical Engineering, Lanzhou Jiaotong University, Lanzhou, Gansu, 730070
}

Keywords: urban development; public fitness equipment; development strategy

\begin{abstract}
Chinese public fitness needs further development. Judging from the current situation, it is still at the level of heavy competition, which leads human, material, and financial resources biased towards competitive sports in terms of funding sources. It mainly relies on government funding. There are not many other sources in fitness venues. The government has a certain amount each year for the public fitness equipment, but when public fitness equipment was put on, it was found that the delivery was not uniform or that some old communities did not put it in the training of social sports instructors. Many social sports instructors did not devote themselves to the guidance of public fitness. The guidance of some fitness clubs in the awareness of the public also needs strong propaganda and fitness guidance. From these existing problems, it is necessary to establish a special public fitness institution and a specific fitness evaluation system to develop our country's public fitness.
\end{abstract}

\section{Introduction}

With the rapid development of Chinese economy and the progress of society, people's work pressure is getting greater and greater, their understanding of physical health is getting deeper and deeper, and more and more people are pursuing health. At present, all cities, towns, and villages in China have different forms of fitness. According to the economic value generated, there are profitable fitness establishments and non-profit fitness establishments. Profitable fitness establishments are mainly concentrated in some national chain stores in cities and towns. Fitness clubs and individual single-storey health clubs, such as the Chinese body-Bally fitness club, Hosa fitness club, and Hengli swimming club, are not the areas for this thesis.

The features of public fitness are mainly embodied in places and facilities for fitness, and are donated through the national, local governments, collectives, or the society. 2. These places and facilities are all non-profit making. They are specifically designed to enhance people's physique and promote health. Third, these places and facilities are public property and do not have private property. These places and facilities are used for fitness and satisfy the broad masses of the people and do not have exclusion insurance and individuality [1].

\section{Analysis of the Status Quo of Public Fitness}

Our sports stadiums include the municipal government and the provincial government. The five cities will be held in Changsha. The government has built a large number of gymnasiums in China, such as Helong Gymnasium, Heyuchang Stadium, Sports New City Stadiums, etc., but none of them are currently open to China. The public fitness, the author learned that the person in charge, they believe that the current lack of ability to open, mainly due to the opening of these gymnasium requires a lot of maintenance funds and management personnel, according to Chinese current economic situation has not been able to develop.

In the work of the transformation of the old city, the development of the new city, and the construction of the Dahe West Pilot Area in Changsha, strict compliance with the requirements of relevant laws and regulations has led to the construction of supporting cultural and sports facilities. Accelerate the construction of the Changsha Stadium according to law. It is forbidden to change the nature and function of the land for public sports facilities that have been planned and constructed. It 
is necessary to step up efforts to solve the problem of the narrow sports grounds in the old town and the insufficiency of sports land per person [2]. 1 The current public stadiums in China mainly include places where the government invests and builds in Park Plaza, community public fitness establishments and some unit buildings to meet the fitness requirements of its employees.

Social sports instructors are a software guarantee for our country's public fitness. While guaranteeing that the people have local and equipment training, they must also exercise guidance. This is the task of social sports instructors, so there are adequate and qualified social sports instructors. Our public fitness is very important. Fitness training For sports workers, they do not need social sports instructors. This group knows how to exercise. However, for the majority of people who are not engaged in sports work, social sports instructors are very important to them. The authors are in some public fitness exercises. The venue used interviews to interview some fitness people and found that many people did not understand how to exercise, what kind of project, what kind of load was in line with what kind of group, and exercise combined with exercise and nutrition, so the social sports instructor was The public has played a very important role in fitness training and is a powerful guarantee for the realization of the "Outline of the National Fitness Program" in China. Through investigation, it has been found that social sports instructors in Chinese fitness venues account for social sports instructors in fitness clubs and other fee-based places. As shown in Table 1, public sports instructors at public gymnasiums that do not charge fees can find that the social sports instructors in Chinese gymnasiums are mainly concentrated in fitness clubs and other charging venues. The proportion of social sports instructors in public fitness venues is very high. Less, according to me personally to some agency Public fitness establishments in the district have found that many fitness establishments do not have social sports instructors at all, and all people spontaneously exercise at fitness establishments. The professional functions of social sports instructors are divided according to the field of work. Their professional functions are divided into reception work, technical guidance, fitness guidance, training, and management and management. Therefore, social sports instructors must have a certain amount of work. With a professional basis and a high overall quality, some amateurs and retired people who do not have the qualifications for social sports instructors simply cannot provide comprehensive guidance to those who do not know how to exercise, and can only conduct guidance from one side and cannot replace a qualified one. Social instructor.

\section{Problems in Public Fitness}

Chinese current public fitness funds are mainly funded by the government. By the end of the year, the Changsha municipal government will strive to meet the public's public fitness, strive to reach a square meter per capita of sports facilities and facilities, and spend a per capita per capita on special funds for physical fitness. The main fitness sites for social investment are In terms of profitability, such as the miracle fitness club, the fitness club in the body, etc., the funds for the construction of sports lottery provident funds for public fitness construction are also very small, the overall funds can not meet the public fitness in our country, government investment is only a guide, can not be thorough Solve the problem. Therefore, only by relying on the attention of various parties in the society and expanding the sources of funds from multiple sources can we solve the issue of public health funds in China [3].

Every year, the government of our country has a certain amount of public fitness equipment. For example, in the year, the government put up more than one piece of fitness equipment for each area of our country. However, when the public fitness equipment was put on, it found that the delivery was uneven or that some old communities had no place. Therefore, public fitness cannot be managed by a single department. It also requires the whole society to collaborate and take this public welfare undertaking as an essential job, so that it can change the current situation.

The number of social sports instructors in China has reached a relatively high level, which is already higher than the proportion of Chinese years. It is mainly the training of secondary social sports instructors. Some of these social sports instructors are between one year old and many social sports. The instructors are all charge-based health clubs, and there are no social sports instructors in 
many places of public fitness venues, or there is a low level of general education. To improve the education of social sports instructors, strengthen the coordination of the age structure of social sports instructors, and launch these social sports instructors to participate in some public fitness guidance, it can meet our country's public fitness social sports guidance.

\section{Development Strategy of Public Fitness}

The country's macro-control over fitness exercises is also very important. From the outbreak of the Opium War to the establishment of the New China, our country has long been in a state of war and the people are in the middle of nowhere. During this period, our country's mass sports are very backward. After the founding of New China, The state attaches great importance to mass sports and once there has been a good momentum of development. Then we encountered the "Great Leap Forward" and "Cultural Revolution" in our country. This has led to the development of mass sports in the deformed development for a long period of time. The "CPC Central Committee Notice on Further Developing Sports" pointed out that sports has a bearing on the health of the people, the prosperity of the nation, and the country's honor. It also helps to increase the ideological awareness of the broad masses of the people, realize the Party's overall mission in the new period, and develop international contacts. Strengthening the unity and friendship with the people of the world and strengthening the national defense force all have a major role. By the 20th century, we will build our country into a sports power, in order to strengthen the nation's physique and lay the foundation for strengthening the country and strengthening the people. In the year, Chinese "Outline for National Fitness Program" and the first "Sports Law" were issued one after another. This more standardized the nationwide fitness program in our country and determined the status of national fitness in China. In recent years, China has also promulgated the "National Fitness One-for-One Project". The State Council has officially approved the year-on-month implementation of the National Fitness Program. From the beginning of the year to the beginning of the year, every year is the National Fitness Day [4].

In the implementation and implementation of the national fitness program, local governments will play a greater role. In terms of manpower, Changsha has trained a strong lineup of social sports instructors. In terms of material resources, fitness equipment has been introduced and laws and regulations have been introduced. The "Notice of Action Plan for Building a Healthy City in China" and "Decision on Further Strengthening Sports in the City", Changsha City is the provincial capital of Hunan Province, and the development of public fitness in our country has played a good role in the national fitness of Hunan Province. Taking the lead, Hunan is a central region of China. Compared with Chinese coastal cities, Changsha's economy is relatively backward and the people's spending power is also at a relatively low level. Therefore, public fitness plays an important role in the national fitness program in Hunan Province. It is very important for the government to control the public fitness in China and establish a good institutional system. China has already proposed to build a healthy city mechanism. 2 These are the series of policies that local governments have put forward to develop Chinese mass sports and have played an active role [4

Under the leadership of the government, full use is made of the human resources of the various units of the urban community and various types of mass sports activities are carried out. The sports functional departments at all levels have systematically carried out mass sports activities in urban communities, and trained them in accordance with the System of Social Sports Instructors' Technical Hierarchies. Social sports instructors shall strengthen the construction of facilities in urban community stadiums, maintain the facilities and facilities that the community has, strengthen the implementation of the acquisition of community sites, assist the community in strengthening the monitoring of the national fitness and fitness, and assist scientific research workers in improving the scientific research achievements and promotion of public fitness in China. We will deepen the construction of laws and regulations for mass sports and strengthen citizens' legal education and publicity on the national fitness program. 1 The functional departments of sports administration should establish a special fund for public fitness, which will be devoted to the construction of public fitness in China, and at the same time implement financial disclosure. 
Chinese public fitness needs a specific implementation, and it can't stay on the slogan or the big framework. It needs to build a concrete public fitness system under the guidance of the macro. These systems are used to assess the development of public fitness in China. At the same time, these systems need to assemble our country's manpower, material resources, financial resources, project characteristics, and fitness characteristics to make full use of social forces and establish a scientific public fitness system for public fitness in China. The construction plays a guiding role, makes the public fitness investment decisions more scientific and rational, and thus produces greater social benefits [5].

\section{Conclusion}

Build a public fitness institution under the leadership of the government, and set up an independent financial department to finance the public fitness. This is conducive to the efficient operation of all aspects of public fitness. Formulate a public fitness assessment system in China so as to quantify and standardize various fitness index systems. Expand the communication and cooperation between public fitness and enterprises, strengthen the source of funds for public fitness, strengthen the training of social sports instructors, implement guidance members in the community to guide the public fitness in the community, strengthen propaganda for public fitness, and expand public awareness of fitness.

\section{References}

[1] Chen Haiyan. Thoughts on the Reform of Sports Administration in China [J]. Sports Culture Guide. 2008 (10)

[2] Li Jiang, Cai Mingming, Deng Xinbo, Wang Kai. Considerations on the Principles and Approaches to the Construction of Sports Fitness and Entertainment Market in Jiangsu Province [J]. Journal of Nanjing Institute of Physical Education (Social Sciences Edition). 2008 (04)

[3] Li Jintian. Research on the Construction of Local National Fitness Regulations [J]. Journal of Beijing University of Physical Education. 2008 (01)

[4] Miao Zhiwen, Qin Yulin, Huang Jinjin, Li Wei. Definition and Transformation of the Management Function of Chinese Sports Government in the New Era [J]. Journal of Beijing Sport University. 2007 (10)

[5] Song Jie. A discussion on the basic theoretical issues of the evaluation of urban community fitness environment [J]. Journal of Beijing University of Physical Education. 2007 (10) 